\title{
KMTase Set7/9 is a critical regulator of E2F1 activity upon genotoxic stress
}

\author{
L Lezina ${ }^{1,2}$, V Aksenova ${ }^{2}$, T Ivanova ${ }^{1}$, N Purmessur ${ }^{1}$, AV Antonov $^{3}$, D Tentler ${ }^{2}$, O Fedorova ${ }^{2}$, AV Garabadgiu², I Talianidis ${ }^{4}$, \\ G Melino ${ }^{2,3,5}$ and NA Barlev ${ }^{*, 1,2,6}$
}

During the recent years lysine methyltransferase Set7/9 ((Su(var)-3-9, Enhancer-of-Zeste, Trithorax) domain containing protein $7 / 9$ ) has emerged as an important regulator of different transcription factors. In this study, we report a novel function for Set7/9 as a critical co-activator of E2 promoter-binding factor 1 (E2F1)-dependent transcription in response to DNA damage. By means of various biochemical, cell biology, and bioinformatics approaches, we uncovered that cell-cycle progression through the G1/S checkpoint of tumour cells upon DNA damage is defined by the threshold of expression of both E2F1 and Set7/9. The latter affects the activity of E2F1 by indirectly modulating histone modifications in the promoters of E2F1-dependent genes. Moreover, Set7/9 differentially affects E2F1 transcription targets: it promotes cell proliferation via expression of the CCNE1 gene and represses apoptosis by inhibiting the TP73 gene. Our biochemical screening of the panel of lung tumour cell lines suggests that these two factors are critically important for transcriptional upregulation of the CCNE1 gene product and hence successful progression through cell cycle. These findings identify Set7/9 as a potential biomarker in tumour cells with overexpressed E2F1 activity.

Cell Death and Differentiation (2014) 21, 1889-1899; doi:10.1038/cdd.2014.108; published online 15 August 2014

Lysine methylation of non-histone proteins has recently emerged as a novel regulatory mechanism to control protein functions. $^{1-4}$ Set7/9 ((Su(var)-3-9, Enhancer-of-Zeste, Trithorax) domain containing protein 7/9) is a founding member of the family of non-chromatin lysine methyltransferases (KMTases). Set7/9 was initially identified as a monomethylase of histone $\mathrm{H} 3$ lysine 4 (H3K4) in vitro. ${ }^{4,5}$ However, we and others showed that the recombinant Set7/9 failed to target nucleosomes for methylation, ${ }^{6-8}$ suggesting that Set7/9 functions as a factor-specific KMTase. There have been several non-histone proteins reported as the substrates for Set7/9, including TAF10 (TATA box binding protein (TBP)associated factor, $30 \mathrm{kDa}){ }^{9}$ oestrogen receptor $\alpha(\mathrm{ER} \alpha),{ }^{10}$ RelA, ${ }^{11}$ PCAF (P300/CBP-associated factor), ${ }^{12}$ Stat3, ${ }^{13}$ Yap, ${ }^{14}$ and Suv39h1 $1{ }^{15}$ However, in most cases the functional significance of this methylation is still not clear. The beststudied targets of Set7/9-mediated methylation are $\mathrm{p} 53^{16}$ and E2 promoter-binding factor 1 (E2F1), ${ }^{17}$ transcription factors involved in regulation of DNA damage response (DDR).

In response to genotoxic stress cancer cells undergo cell-cycle arrest either in G1/S or G2/M or in both checkpoints. The presence of intact p53 in cancer cells mediates transient G1/S checkpoint arrest, ${ }^{18,19}$ which allows cells to repair the damaged DNA before replication or, if the amount of damage is insurmountable, drives cells into apoptosis. ${ }^{20,21}$

On the contrary, the activity of the E2F family transcription factors, especially E2F1, drives cells from the G1/S block to mitosis. ${ }^{22,23}$ Transcriptional activity of E2F1, in turn, is repressed by the retinoblastoma protein $(R b)$ family proteins. ${ }^{24-26}$ The latter are inactivated by phosphorylation mediated by cyclin-dependent kinase (Cdk2) and Cdk4/ Cdk6 cell-cycle kinases. ${ }^{27-29}$ The E2F1 transcription factor drives cell-cycle progression by activating the transcription of CCNE gene, whose product is essential for Cdk2 kinase activity. ${ }^{30}$ Cdk2/cyclin E and Cdk4/6 partnered with various forms of cyclin $D$ are the principal kinases required for replication of DNA. ${ }^{31,32}$ In addition, E2F1 regulates a number of genes involved in DNA repair, chromosomal stability, and apoptosis. $^{33,34}$

Importantly, E2F1 induces transcription of $\mathrm{p} 53,{ }^{35}$ whereas p53 represses the activity of E2F1, thus forming a negative feedback loop. ${ }^{23,36}$

The functional outcome of Set7/9-mediated methylation of p53 and E2F1 is diametrically opposite for these two proteins: methylation of p53 on K372 stabilises the protein by inducing its subsequent acetylation, ${ }^{37}$ yet methylation of E2F1 on

\footnotetext{
${ }^{1}$ Department of Biochemistry, University of Leicester, Leicester LE1 9HN, UK; ${ }^{2}$ Molecular Pharmacology Laboratory, Saint-Petersburg Institute of Technology, Saint-Petersburg 190013, Russia; ${ }^{3}$ MRC Toxicology Unit, Leicester LE1 9HN, UK; ${ }^{4}$ B.S.R.C. 'Alexander Fleming', Varkiza 16602, Greece; ${ }^{5}$ Faculty of Medicine, University of Rome 'Tor Vergata', Rome 00133, Italy and ' ${ }^{6}$ Gene Expression Laboratory, Institute of Cytology, Saint-Petersburg 194064, Russia

*Corresponding author: NA Barlev, Department of Biochemistry, University of Leicester, Lancaster Road, Leicester LE1 9HN, UK. Tel: +44 0 1162297120; Fax: +44 0 1162297231; E-mail: nb155@le.ac.uk

Abbreviations: DDR, DNA damage response; Set7/9, (Su(var)-3-9, Enhancer-of-Zeste, Trithorax) domain containing protein 7/9; E2F1, E2 promoter-binding factor 1; KMTase, lysine methyltransferase; TAF10, TATA box binding protein (TBP)-associated factor, $30 \mathrm{kDa}$; ER $\alpha$, oestrogen receptor; PCAF, P300/CBP-associated factor; $\mathrm{Rb}$, retinoblastoma protein; Cdk, cyclin-dependent kinase; BrdU, bromodeoxyuridine; siRNA, small interfering RNA; shRNA, short hairpin RNA; ChIP, chromatin immunoprecipitation; HDAC, histone deacetylase; HSP90, heat shock protein 90; PARP, poly (ADP-ribose) polymerase; RPMI, Roswell Park Memorial Institute; FBS, foetal bovine serum; DMEM, Dulbecco's modified Eagle's medium; RIPA, radioimmunoprecipitation assay; SDS-PAGE, SDS-polyacrylamide gel electrophoresis; PBS, phosphate buffer saline; BSA, bovine serum albumin; FACS, fluorescence-activated cell sorting

Received 06.12.13; revised 01.5.14; accepted 09.6.14; Edited by M Piacentini; published online 15.8.14
} 
$\mathrm{K} 185^{17}$ on the contrary, interferes with acetylation, promotes its ubiquitylation and subsequent degradation via the $26 \mathrm{~S}$ proteasome. ${ }^{38,39}$ It has also been shown that, in addition to p53 and E2F1, Set7/9 affects other substrates via regulating their protein stability either positively $(E R \alpha)^{10}$ or negatively (DNMT1, RelA). ${ }^{40,41}$

In this study, we report a novel function for Set7/9 as a critical co-activator of E2F1-dependent transcription in response to DNA damage. By means of various biochemical, cell biology, and bioinformatics approaches, we conclude that cell-cycle progression through $\mathrm{G} 1 / \mathrm{S}$ phase of tumour cells upon DNA damage is defined by the threshold of expression of both E2F1 and Set7/9. Our screening of the panel of lung tumour cell lines suggests that these two factors are critically important for transcriptional upregulation of the CCNE gene product and hence successful exit from the G1/S checkpoint arrest. These findings identify Set7/9 as an attractive target for pharmacological inhibition with small molecules.

\section{Results}

Inactivation or ablation of Set7/9 results in G1/S arrest upon DNA damage. Since Set7/9 affects both p53 and E2F1 transcription factors whose activities regulate cell-cycle regulation and apoptosis, we reasoned that Set7/9 also must have a role in execution of cell-cycle checkpoints in response to DNA damage. To test this hypothesis, we analysed cellcycle distribution of non-small human lung carcinoma cells, H1299, with short hairpin RNA (shRNA)-mediated knockdown of Set7/9 (H1299 Set9KD), along with parental cells transfected with control shRNA (H1299) (Figure 1a). These cells are negative for p53, but express E2F1. To induce DNA damage, cells were treated with doxorubicin for the indicated periods of time. Expectedly, H1299 cells exhibited cell-cycle arrest mostly in S and G2 phases, which is typical for $\mathrm{p5} 3^{-}$ cells that lack G1/S checkpoint. ${ }^{18}$ On the contrary, H1299 Set9KD cells displayed a stronger G1/S-phase arrest compared with the control cells.

We also wanted to expand our observations on $\mathrm{p} 53^{+}$cells. We chose ${\mathrm{p} 53^{+}}$human osteosarcoma U2-OS cells, which exhibit a more pronounced arrest in G2/M in response to DNA damage due to overexpression of Wip1 phosphatase. ${ }^{42}$ Therefore, U2-OS represents a convenient model to study effects of Set7/9 on G1/S arrest after DNA damage in the presence of $\mathrm{p53}$. Thus, we generated cells expressing (U2OS control) or lacking Set7/9 (U2OS Set9KD). To examine the role of lysine methylation activity of Set7/9 in cell cycle, we generated shRNA-resistant catalytically active and inactive (Set7/9wt and Set7/9mut, respectively) expression constructs and overexpressed them in U2OS Set9KD cells (Figure 1b). Whereas U2-OS control cells showed mostly G2/M arrest, cells lacking Set7/9 were preferentially arrested in G1/S. Moreover, only wild-type Set7/9, but not Set7/9 mut, was able to restore the original phenotype of parental cells. Importantly, ectopic Set7/9 wild-type and the mutant proteins were expressed at the comparable levels (Figure 1c).

Notably, an accumulation of Set7/9 ${ }^{-}$cells in G1/S after genotoxic stress was observed in various cell lines irrespectively of the p53 status and source of DNA damage (doxorubicin, X-rays, or UV) (Supplementary Figures 1-3).
Our results suggested two plausible scenarios: (i) the attenuation of Set7/9 expression or its activity compromised the G2/M checkpoint arrest and hence, cells were accumulated at the G1/S boundary after the round of mitosis; (ii) Set7/ 9-deficient cells were never able to exit G1 after DNA damage and thus could not proceed through $S$ phase to G2. To discriminate between these possibilities, we performed several experiments. First, using phospho-serine 10 in histone H3 (H3-S10-phos) staining as a marker of mitosis, we counted at different time points the number of mitotic cells in U2-OS control and U2-OS Set7/9KD cells after their treatment with the indicated doses of doxorubicin (Figure 1d). A much lower number of U2-OS Set7/9KD cells entered mitosis at $0.5 \mu \mathrm{M}$ of doxorubicin treatment compared with the control cells. These data suggest that Set $7 / 9^{-}$cells are likely arrested in G1/S. To confirm this, we stained U2-OS and U2-OS Set7/9KD cells with bromodeoxyuridine (BrdU) after treatment with doxorubicin (Figure 1e). BrdU is incorporated only in the newly synthesised DNA and thus manifests the S-phase transition. While U2-OS control cells resume their cell cycle after $24 \mathrm{~h}$ post doxorubicin treatment, U2-OS Set7/9KD cells were halted in G1 and G2 phases without any visible population of cells that newly entered $S$ phase. This suggests that the ablation of Set7/9 not only imposes G1/S arrest but also blocks the transition through $S$ phase. Collectively, these results strongly argue that lysine methylation by Set7/9 has an important role in regulating cellcycle progression upon DNA damage.

Set7/9 regulates the level of cyclin E expression. It is well established that the driving force behind the transition of cells from $\mathrm{G} 1$ to $S$ phase is the kinase activity of the Cdk2/cyclinE and Cdk4/cyclin D complexes. Accordingly, we tested the ability of Cdk2 and Cdk4 immunoprecipitated from U2-OS control and Set7/9KD cells to phosphorylate histone $\mathrm{H} 1$, a common substrate for various kinases. ${ }^{43}$ Since p53 is known to inhibit the activity of various cdks via p21/CIP, ${ }^{44}$ we also examined U2-OS cells with knockdown of p53 expression (U2-OS p53KD) (Figure 2a). We found that control U2-OS cells displayed high cdk2 activity, which decreased upon DNA damage. However, in Set7/9KD cells the activity of Cdk2 was somewhat lower even in the absence of DNA damage and was almost ameliorated after $24 \mathrm{~h}$ of doxorubicin treatment. p53-deficient cells showed intermediate levels of Cdk2 activity, higher than in Set7/9KD cells, but lower than in the control cells (Figure 2a, upper). This is due to their faster transition through $\mathrm{G} 1 / \mathrm{S}$ phase, where the activity of cdk2 is the highest. ${ }^{45}$ On the contrary, the activity of cdk4, another principal kinase that drives G1/S transition, after DNA damage was comparable in both U2-OS control and Set7/9KD cells (Figure 2a, lower). Put together, these results suggest that Set7/9 specifically modulates the activity of the Cdk2/cyclin E complex upon DNA damage.

Kinase activity of the Cdk2 complex depends on the protein levels of both Cdk2 and cyclin E. Thus, we tested the levels of Cdk2 and cyclin E expression in control, Set7/9KD, and p53KD U2-OS cells before and after DNA damage (Figure 2b). We found that the levels of cdk2 expression were comparable in all three cell lines, whereas the levels of cyclin E differed drastically between the cell lines (Figure 2b, middle 

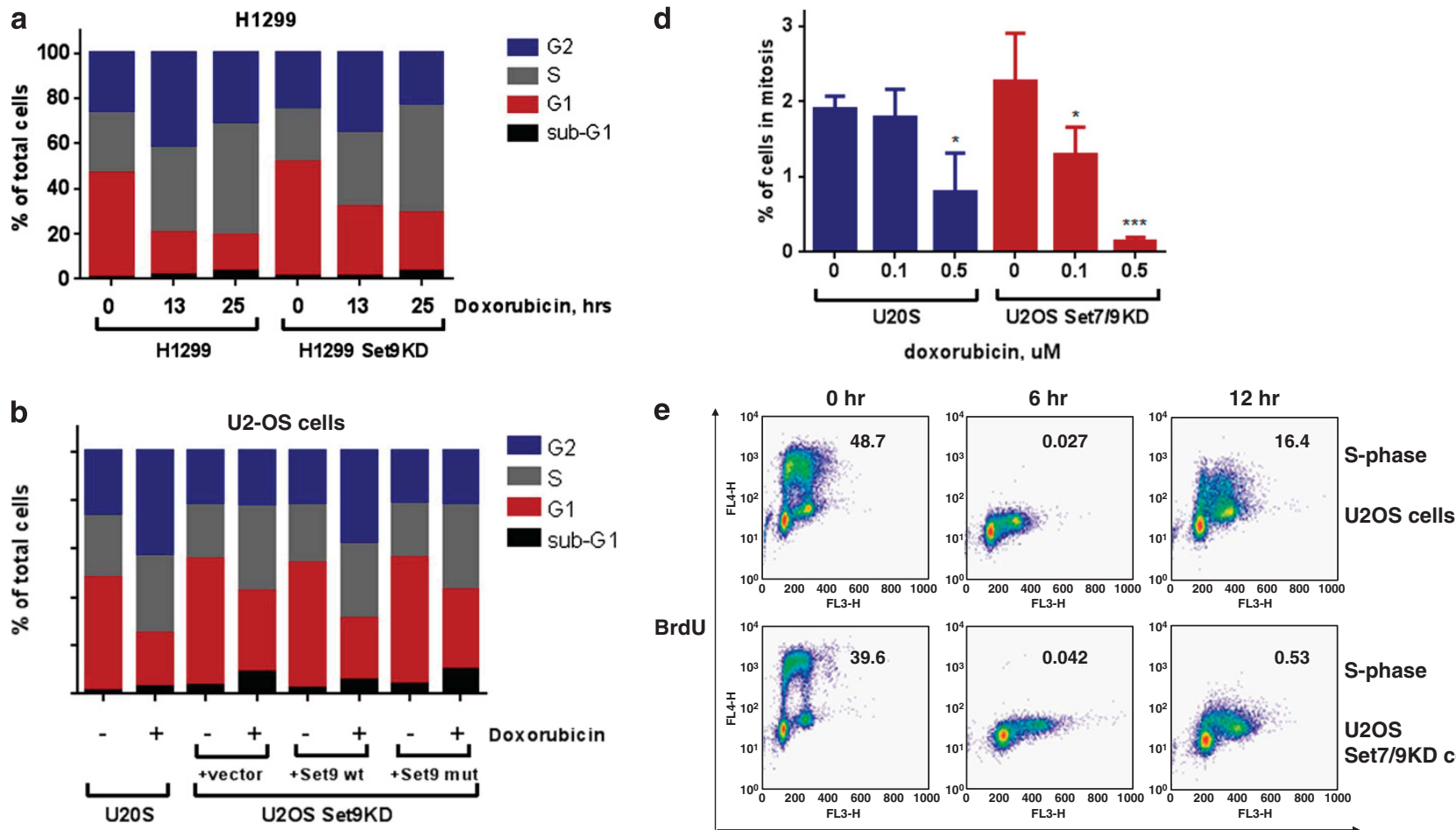

BrdU
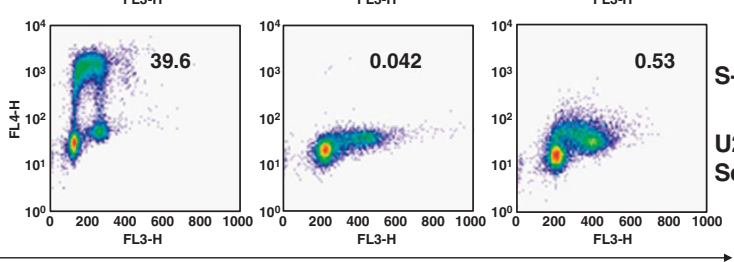

S-phase

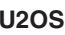

Set7/9KD cells

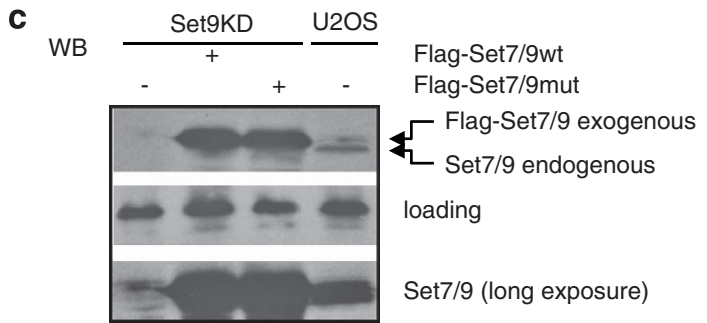

7-AAD

Figure 1 Set7/9 affects cell-cycle distribution of tumour cells upon DNA damage. (a) Human H1299 lung adenocarcinoma cells stably expressing shRNA against Set7/9 or control shRNA were treated with doxorubicin for the indicated periods of time. The resulting cells were fixed, stained with propidium iodide and analysed for cell-cycle distribution. (b) Human osteosarcoma U2-OS cells were treated or non-treated with $0.5 \mu \mathrm{M}$ doxorubicin for $14 \mathrm{~h}$ and analysed for cell-cycle distribution as described above. In parallel, U2-OS stably expressing shRNA against Set7/9 (U2OS Set9KD) were transfected with an empty vector, or the one expressing Set7/9wt, or Set7/9 mut (H293A). Transfected cells were treated as control U2OS cells and subjected to cell-cycle analysis. Statistical analysis was done by one-way ANOVA. All treated samples were compared with the untreated ones. Also, U2-OS Set7/9KD cells were compared with U2-OS control cells at 0 time point. Abbreviations: ${ }^{*} P<0.05,{ }^{* *} P<0.01$, ${ }^{* * *} P<0.001$; ${ }^{* * \star *} P<0.0001$. (c) Western blot analysis of ectopic expression of Set7/9 wild-type and H279A mutant in U2-OS Set7/9KD cells. Levels of endogenous Set7/9 in nontransfected U2-OS and U2-OS Set7/9KD cells are also shown. Actin served as a loading control. (d) U2-OS cells expressing control or Set7/9-specific shRNA were pulsetreated with the indicated amounts of doxorubicin for $2 \mathrm{~h}$ followed by incubation for 16, 24, and $48 \mathrm{~h}$. At each time point the number of mitotic cells was determined for both cell lines using phospho-S10-H3 staining. The total number of cells was also calculated. The percentage of mitotic cells was calculated as an average of mitotic cells obtained for each time point divided by the total number of cells in each case. (e) U2-OS control (U2OS cells) and U2-OS cells expressing shRNA-Set7/9 (U2OS Set9KD cells) were treated with $0.5 \mu \mathrm{M}$ doxorubicin for the indicated times followed by labelling with BrdU. Subsequently, cells were permeabilised, treated with DNAse, stained with anti-BrdU antibodies conjugated to FITS, followed by staining with 7-AAD to visualise DNA. The resulting samples were analysed by FACS. The numbers shown indicate the percentage of cells in S phase

panel). While control U2-OS cells accumulated cyclin E after DNA damage, very little accumulation was observed in DNA damage-treated Set7/9KD cells. Expectedly, p53 stabilisation in response to DNA damage was compromised in Set7/9KD cells, as published previously. ${ }^{6}$ Notably, Cdk4/cyclin D1 levels in the control and Set7/9KD cells were comparable, indicating that this kinase complex did not affect the arrest of Set7/9KD cells in G1/S phase (Figure 2c). Similarly, a low level of cyclin $E$ was detected in p53KD cells both before and after DNA damage. ${ }^{46}$ The latter effect can be explained by the fact that the cellular amount of cyclin $E$ decreases after the passage of cells through $\mathrm{S}$ phase. Note, that $\mathrm{p} 53^{-}$cells undergo G2/M arrest in response to double-strand breaks and thus pass through $\mathrm{G} 1 / \mathrm{S}$ phase quickly.

In agreement with previously published results Set7/9KD cells contained increased levels of E2F1 both before and after DNA damage compared with the levels of E2F1 in U2-OS control cells, where its expression is repressed by $p 53^{47}$ (Figure 2b). Accordingly, E2F1 levels were higher in p53KD cells compared with the control cells (Figure $2 \mathrm{~b}$ ).

Given that the constitutive knockdown of Set7/9 may affect gene expression indirectly, we generated an inducible Tet-on 


\section{a}

Kinase assay for Cdk2

Time, doxo $0 \begin{array}{llllll}0 & 24 & 0 & 24 & 0 & 24\end{array}$

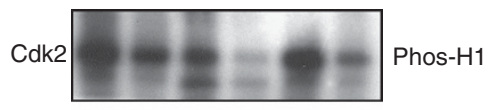

Cdk4

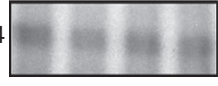

$\overline{\text { control }} \overline{\text { set7/9KD }} \overline{\text { p53KD }}$

b

Western blotting

Time, doxo $\quad 0 \quad 24 \quad 0 \quad 24 \quad 00 \quad 24$

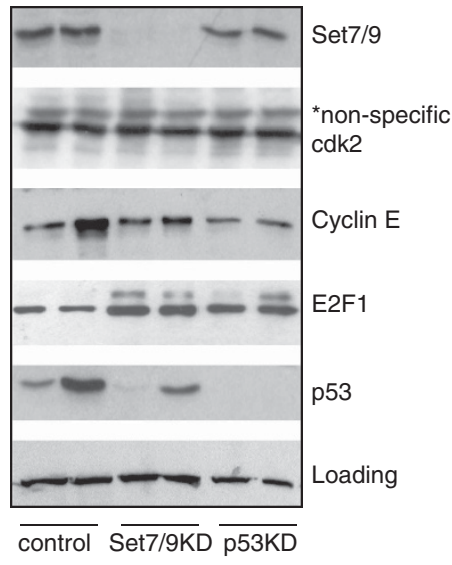

C

Western blotting

Time, doxo

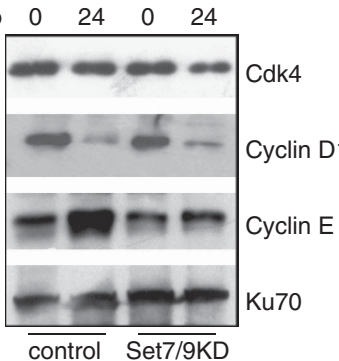

d U2-OS Tet-on cells

Tet

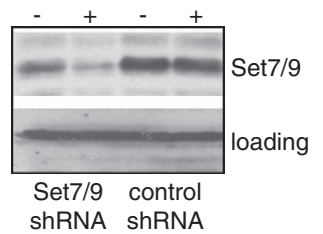

e

Time, doxo $0 \begin{array}{llllll}0 & 14 & 24 & 0 & 14 & 24\end{array}$

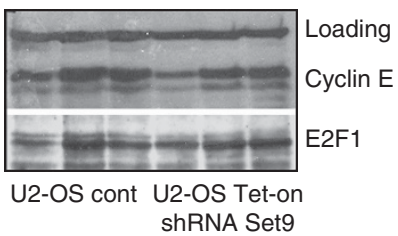

Figure 2 Set7/9 controls Cdk2 activity by affecting the expression of cyclin E. (a) U2-OS parental control cells and cells with knockdown expression of Set7/9 and p53 were treated with doxorubicin for the indicated times and subject to immunoprecipitation with anti-cdk2 or anti-cdk4 antibodies. The resulting immunopurified Cdk2/cyclin E and cdk4/cyclin D complexes were analysed for their ability to phosphorylate H1. (b) Western blot analysis of the cell lines indicated above for the levels of expression of Set7/9, cdk2, cyclin E, E2F1, and p53. Actin signal was used as a loading control. (c) Western blot analysis of U2-OS and U2-OS Set7/9- cells (Set7/9KD) treated with doxorubicin for the indicated times and subject for immunoblotting with cdk4, cyclin D1, and cyclin E antibodies. Ku70 was used as a normalisation control. (d) Tet-on U2-OS cells with inducible expression of control shRNA or shRNA against Set7/9 were induced with $2 \mu \mathrm{g} / \mathrm{ml}$ doxycycline or tetracyclin (Tet) for 3 days before assessing the efficiency of knockdown of Set7/9 by western blotting. Actin signal was used as a loading control. (e) The abovementioned cells were treated with doxorubicin and analysed for the levels of cyclin E and E2F1 by western blotting

U2-OS cell line and found that, similar to our previous results, activation of Set7/9-specific shRNA attenuated the level of cyclin E expression in response to doxorubicin compared with control shRNA-expressing cells (Figures $2 d$ and e). The kinetics of E2F1 accumulation after DNA damage in U2-OS control cells differed from that in U2-OS Set7/9- cells. In the control cells, E2F1 levels declined by $24 \mathrm{~h}$ due to repression mediated by $\mathrm{p} 53$. In contrast, the level of E2F1 in Set7/9 cells, where the function of p53 is compromised, peaked at $24 \mathrm{~h}$ (Figure 2e).

Set7/9 regulates E2F1-mediated transcription. Next, we wanted to find out whether the attenuation of cycin $E$ expression in Set7/9KD cells occurs on the level of protein stability or on the level of transcription. To address this question, we employed luciferase reporter assay using the cyclin E promoter luciferase construct. Since E2F1 is the major regulator of CCNE transcription we also used a cyclin E promoter deletion mutant construct that lacks E2F1 binding sites (Figure 3a). As shown in Figure 3, deletion of the E2F1 responsive element from the cyclin $\mathrm{E}$ promoter (cycE mut) luciferase construct resulted in a significant attenuation of transactivation in both $\mathrm{H} 1299$ and U2-OS cells compared with wild-type promoter. DNA damage increased transcription of cyclin E promoter in both $\mathrm{H} 1299$ and U2-OS cells (Figures $3 c$ and e). This is consistent with the fact that E2F1 is activated by DNA damage. ${ }^{23}$ In contrast, abrogation of Set7/9 expression in both cell types resulted in a significant reduction of cyclin $\mathrm{E}$ transcription.

To validate our results of luciferase assays, we assessed the effect of Set7/9 on expression of the endogenous CCNE1 gene in U2-OS and U2-OS Set7/9KD cells (Figure 3f). In addition, we also examined expression of another target of E2F1, TP73 (Figure 3g). Transcription of CCNE1 was elevated upon DNA damage in control cells, but did not change in Set7/9 KD cells, supporting the notion that Set7/9 is important for expression of cyclin E. In contrast with CCNE1, transcription of TP73 was enhanced by the ablation of Set7/9, suggesting that Set7/9 may regulate E2F1 target genes differently. Collectively, these results indicate that Set7/9 is required for transcriptional activation of CCNE1 by E2F1 in response to DNA damage.

Next, we thought to examine whether E2F1 together with Set7/9 contributes to the regulation of cyclin $E$ and $p 73$ 


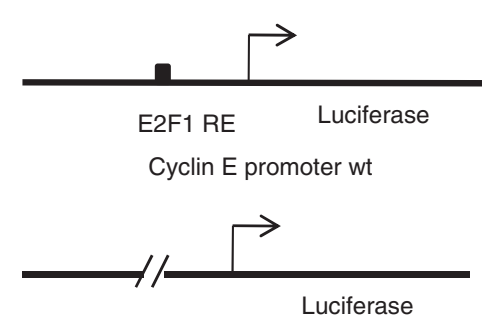

Cyclin E promoter mut

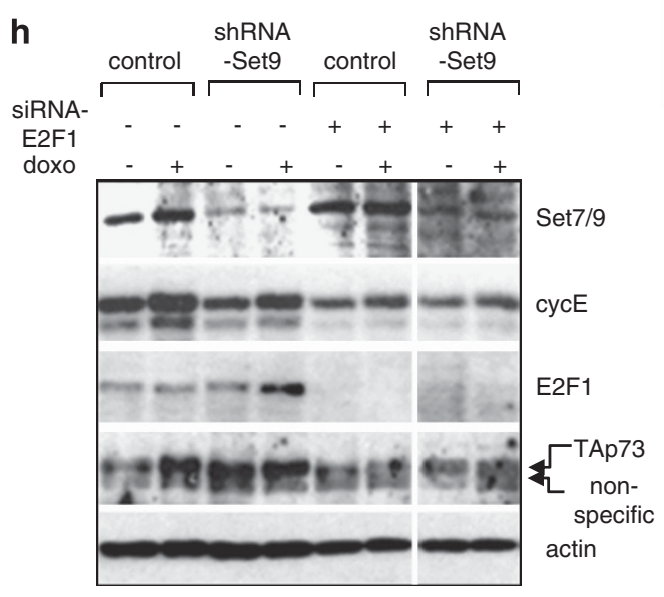

b

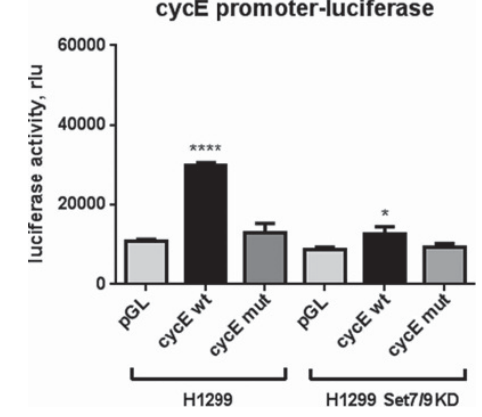

d

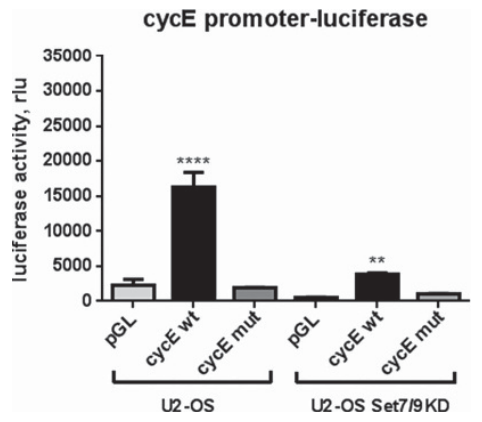

C

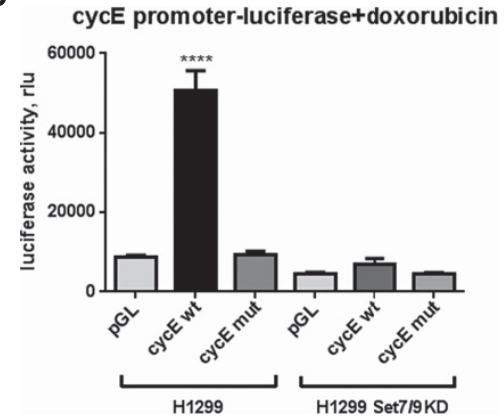

e

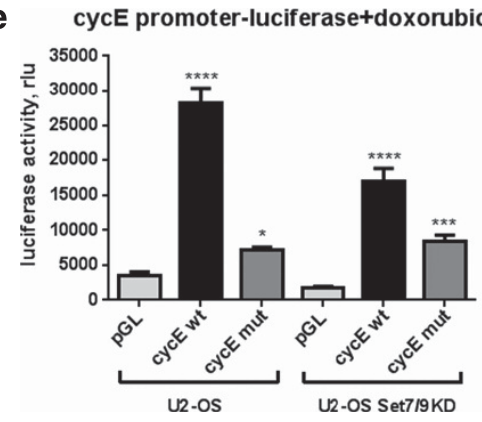

RT-PCR expression

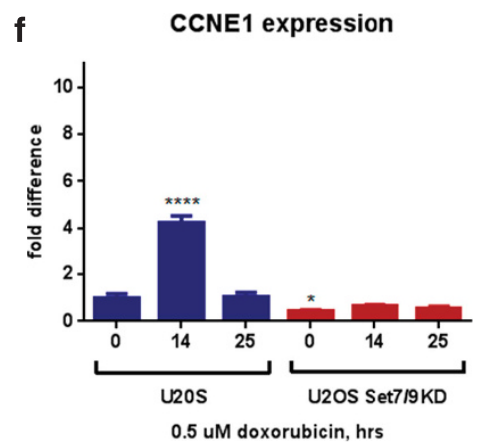

g

p73 expression

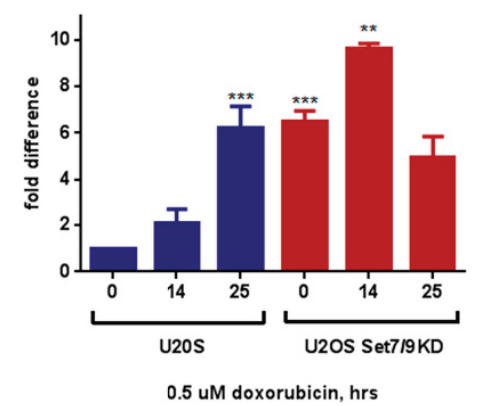

Figure 3 Set7/9 is a transcriptional co-regulator of E2F1. (a) The scheme of luciferase reporter plasmids bearing the cyclin E promoter fragments either containing E2F1 response element (E2F1 RE) (cycE wt) (upper), or lacking it (cycE mut) (lower) is shown. (b and c) H1299 or H1299 Set7/9- (Set9KD) cells transfected with either wild-type or mutant cycE reporter plasmid were not treated or treated with $0.5 \mu \mathrm{M}$ doxorubicin, respectively. Following incubation, cells were lysed and assayed for luciferase activity. The normalisation of efficiency of transfection was carried out based on the levels of activity of transfected beta-galactosidase. (d and e) U2-OS control (U2-OS) or U2-OS Set7/9 ${ }^{-}$ (Set9KD) cells transfected as above were not treated or treated with doxorubicin as described above to assay for luciferase activity. (f and g) U2-OS control (U2-OS) or U2-OS Set7/9- (Set9KD) cells treated with doxorubicin for the indicated periods of time were analysed by RT-PCR for the levels of expression of CCNE1 (f) and TP73 (g) genes. Expression levels of actin were used for normalisation. Statistical analysis was done by one-way ANOVA. Cells that expressed cyclin E promoter constructs were compared with the ones that expressed pGL2 empty vectors. Also, U2-OS Set7/9KD and U2-OS control cells were compared. Abbreviations are the same as in Figure 1d. (h) E2F1 and Set7/9 regulate cyclin E and p73 expression on the protein level. U2-OS control and Set7/9KD cells were transiently knocked down for E2F1 by specific siRNA. The efficiency of Set7/9 and E2F1 knockdowns was controlled by westerns. The levels of cyclin E and p73 expression before and after doxorubicin treatment (doxo) were measured by western blotting using specific antibodies. Note, that the antibody against p73 consistently produced non-specific background (marked as non-specific)

expression on the protein level. To address this question, we transiently knocked down E2F1 by small interfering RNA (siRNA) both in U2-OS control and in Set7/9KD cells and measured the levels of cyclin $E$ and p73 expression before and after DNA damage (Figure $3 \mathrm{~h}$ ). We found that in the absence of E2F1 the levels of cyclin E were lower in both U2-OS control and Set7/9KD cells before and after DNA damage, suggesting that E2F1 is the principal regulator of cyclin E expression. Ectopic expression of Set7/9 in E2F1knockdown cells (data not shown) did not restore the level of cyclin E, indicating that Set7/9 operates upstream of E2F1.
Set7/9 regulates E2F1 binding and histone modifications on the target promoters. To investigate how Set7/9 affects the transcriptional activity of E2F1, we performed a series of chromatin immunoprecipitation (ChIP) assays on promoters of the CCNE1 and TP73 genes (Figure 4). Expectedly, DNA damage increased E2F1 binding to promoters of both genes. However, Set7/9 affected the DNA binding ability of E2F1 only moderately (Figure $4 a$, right and left panels), suggesting that the regulation occurs not on the level of DNA binding but on the level of chromatin modifications. Set7/9 did not affect the levels of K4 mono-methylation of histone $\mathrm{H} 3$ (H3K4Me1) 

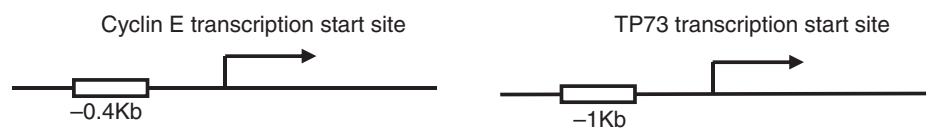

ChIP assay
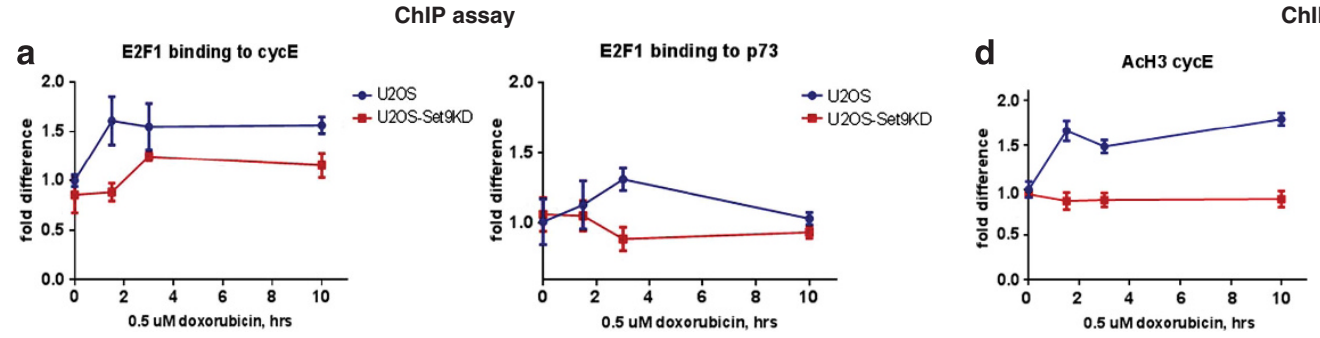

ChIP assay
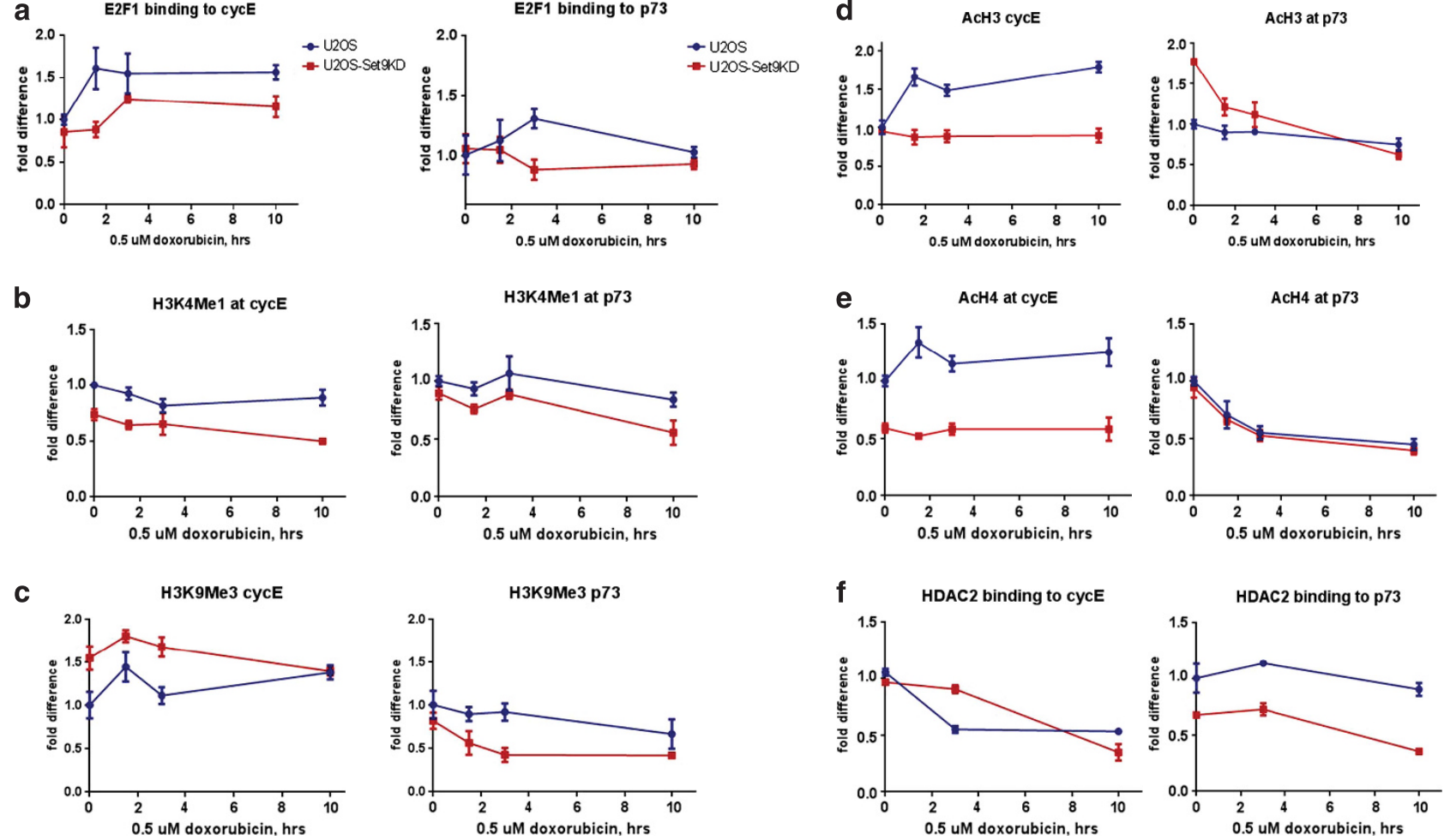

Figure 4 Set7/9 affects histone modifications in the promoters of E2F1-dependent genes. The schemes of amplicons specific for the promoter regions of CCNE1 and TP73 relative to the start site are shown. ChIP assay for E2F1 (a), H3K4 mono-methylation (b), H3K9 tri-methylation (c), AcH3 (d), AcH4 (e), and HDAC2 (f) at the promoters of CCNE1 (left) and TP73 (right) genes. PCR signal in the untreated U2-OS control cells was arbitrary set as 1. Time periods of doxorubicin treatment are indicated. Blue lines denote U2-OS wild-type cells and the red ones -Set7/9 KD cells

(Figure $4 b$ ), supporting the notion that Set7/9 is not able to methylate chromatin. Interestingly, K9 tri-methylation of histone $\mathrm{H} 3(\mathrm{H} 3 \mathrm{~K} 9 \mathrm{Me} 3)$, which is a repressive chromatin mark, was elevated for the promoter of CCNE1 in Set7/9KD cells compared with control U2-OS cells (Figure 4c, left), thus correlating with its decreased transcription in Set $7 / 9^{-}$cells (Figure 3f). The TP73 gene, which, in contrast to CCNE1, is repressed in control cells but becomes de-repressed in Set7/ 9KD cells (Figure $3 \mathrm{~g}$ ), displayed reverse correlation, that is, the level of $\mathrm{H} 3 \mathrm{~K} 9 \mathrm{Me} 3$ was higher in the control cells compared with Set7/9- cells (Figure 4c, right). Next, we tested the dynamics of chromatin activating modifications, such as acetylation of histone $\mathrm{H} 3(\mathrm{AcH} 3)$ and $\mathrm{H} 4(\mathrm{AcH} 4)$. The levels of $\mathrm{AcH} 3$ and $\mathrm{AcH} 4$ signals on the CCNE1 promoter were increased by DNA damage and were higher in the control compared with Set7/9KD cells (Figures $4 d$ and e, left panels). On the contrary, DNA damage attenuated both $\mathrm{AcH} 3$ and $\mathrm{AcH} 4$ levels on the TP73 promoter (Figures $4 \mathrm{~d}$ and e, right panels). Moreover, the initial level of AcH4 in Set7/ 9KD cells was higher in Set7/9 KD compared with U2-OS control cells (Figure 4d, right). These data paralleled the binding kinetics of histone deacetylase 2 (HDAC2) to CCNE1 and TP73 promoters (Figure 4f, compare left and right panels). HDAC2 binds HDAC1 to form a repressive complex to deacetylate histones. ${ }^{48}$ Taken together, the results of ChIP assay suggest that Set7/9 differently regulates transcription of E2F1-dependent genes by modulating the levels of chromatin modifications.

In silico bioinformatics analysis uncovers the E2F1-Set7/9 axis in lung tumour. It is known that E2F1 can have both positive and negative roles in tumour progression, by either forcing the proliferation, or inducing apoptosis, respectively. ${ }^{49}$ Therefore, the overall output of the E2F1 function may differ depending on a specific type of cancer. ${ }^{50}$ Data mining of the literature coupled with the bioinformatics approach ${ }^{51,52}$ have established E2F1 as an oncogene in lung cancers (Eymin et al..$^{53}$ and Huang et al..$^{54}$ Supplementary Data; Supplementary Figure S4 and data not shown). Therefore, we performed our next experiments using lung tumour cell lines.

Since Set7/9 negatively regulated TP73 expression, we questioned whether this negative correlation affected the survival of patients with lung cancer. Thus, we implemented a statistical procedure, which divided the patients into two cohorts. The first one was enriched with positive correlation between expression levels of Set7/9 and TP73, while all the other patients formed the second cohort. To identify statistical differences in survival outcome between these two groups, 
the $R$ statistical package ( $R$ Foundation for Statistical Computing, Vienna, Austria) was used to perform statistical tests and to derive the $P$-value (for full details of the procedure, see Celardo et al. ${ }^{55}$ Two different lung cancer data sets of patients with a strong positive correlation between Set7/9 and TP73 showed poor survival outcome compared with the cohort where Set7/9 and TP73 exhibited a strong negative correlation (Figure 5). Similar results were obtained for breast cancer patients (Figure 5; Supplementary Data). Collectively, these results suggest that disregulation of Set7/9 activity, which is manifested by the loss of TP73 repression, in the tumours where E2F1 has an oncogenic role,that is, lung and breast tumours, negatively correlates with the survival of patients.

Both E2F1 and Set7/9 are necessary for efficient activation of cyclin $\mathbf{E}$ transcription. On the basis of our in silico results, we screened seven lung cancer cell lines with different p53 statuses for the levels of Set7/9, E2F1, and cyclin E expression (Supplementary Data; Supplementary Table 1). These data were then correlated with cell cycle and apoptotic response to DNA damage in the cell lines examined (Figure 6). Collectively, the results of experiments presented in Figure 6 suggest that the levels of cyclin $E$ expression depended on the presence of both Set7/9 and
E2F1 but were not affected by p53 (Figure 6a). For example, low expression of Set7/9 in H520 and H1650 cells correlated with very low levels of expression for cyclin $\mathrm{E}$, irrespective of the E2F1 status. Yet, H460 cells expressed normal level of Set7/9, but an attenuated level of E2F1. As a result, these cells poorly expressed cyclin E. Moreover, the level of cyclin E expression correlated strongly with the cell-cycle profiles of the cell lines examined (Figure 6b). Specifically, those cell lines that expressed low levels of cyclin $E$ underwent cellcycle arrest preferentially in G1/S phase and the ones that expressed high levels of cyclin E were arrested in G2/M after DNA damage.

To confirm that the correlations between Set7/9, E2F1 and cyclin $\mathrm{E}$ expression are meaningful in respect to cell-cycle progression, we transiently knocked down E2F1 expression in H522 cells (high expression of E2F1 and Set7/9) and measured the level of cyclin $E$ expression by western blotting before and after DNA damage (Figure 6c). The attenuation of E2F1 expression resulted in a significant decrease in cyclin $\mathrm{E}$. Importantly, levels of Set7/9 did not change upon siRNA-E2F1 treatment. Collectively, these data establish a functional link between the expression of cyclin E, E2F1, and Set7/9.

Furthermore, the ability of these cells to undergo apoptosis solely depended on the presence of E2F1 and wild-type p53,

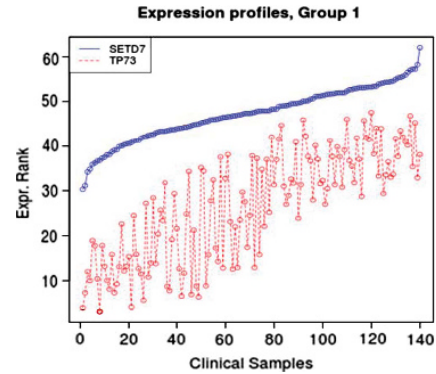

Inverse correlation between SETD7 and TP73 expression in lung cancer, where E2F1 is an oncogene, increases survival on two different data sets

Group=1: green, strong positive correlation (0.78) between SETD7 and TP73 Group=2: red, no (ornegative) correlation $(-0.64)$ between SETD7 and TP73

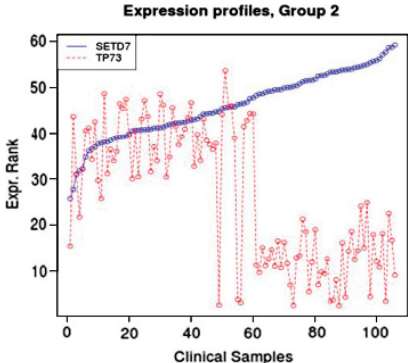
73

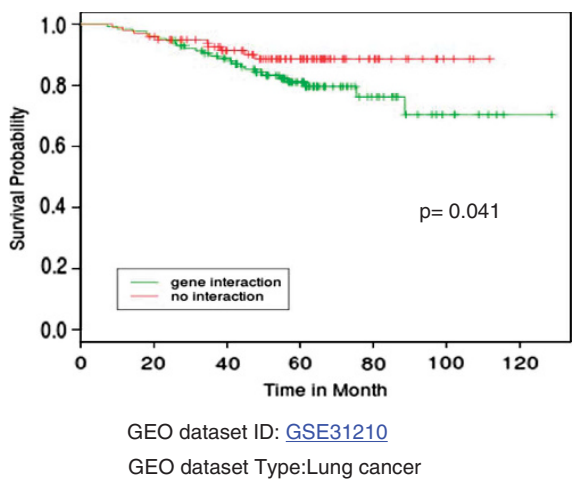

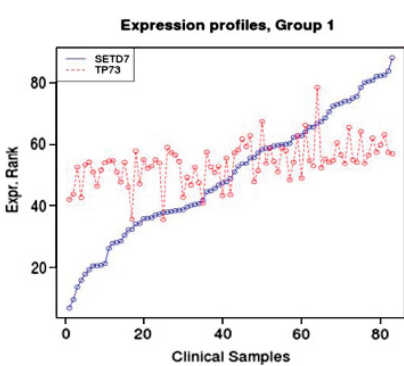

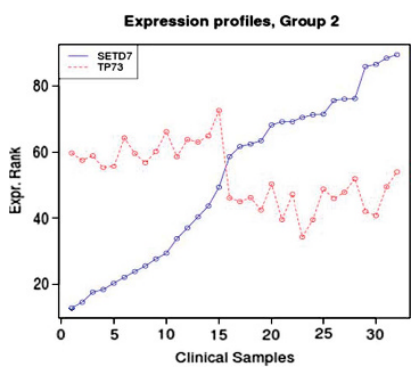

Group=1: green, strong positive correlation (0.51) between SETD7 and TP73 Group=2: red, no (ornegative) correlation (-0.69) between SETD7 and TP73

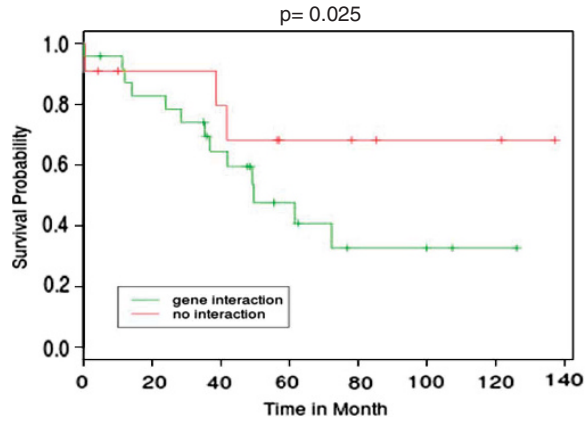

GEO dataset ID: GSE36471

GEO dataset Type: lung cancer

Figure 5 Inverse correlation between Set7/9 and TP73 expression, as judged from two lung cancer data sets (GSE31210, left and GSE36471, right), increases survival of patients. A statistical procedure was implemented to divide the patients with lung cancer into two cohorts. The first one (Expression profiles, Group 1) was enriched with the positive correlation between expression levels of Set7/9 (blue dots) and TP73 (red dots). The second group of patients with negative correlation (Expression Profiles, Group 2) formed the second cohort. The number of clinical samples for each group is indicated below. To identify statistical differences in survival outcome between these two groups (lower panel), the $\mathrm{R}$ statistical package was used to perform statistical tests and to derive the $P$-value (shown inside). The $Y$ axis denotes relative survival probability. The $\mathrm{X}$ axis denotes the time of survival in months. Vertical bars on the graph curves indicate the survival measurements. A strong positive correlation between Set7/9 and TP73 (green line) shows poor survival outcome compared with the negative correlation between these two genes (red line) 
a

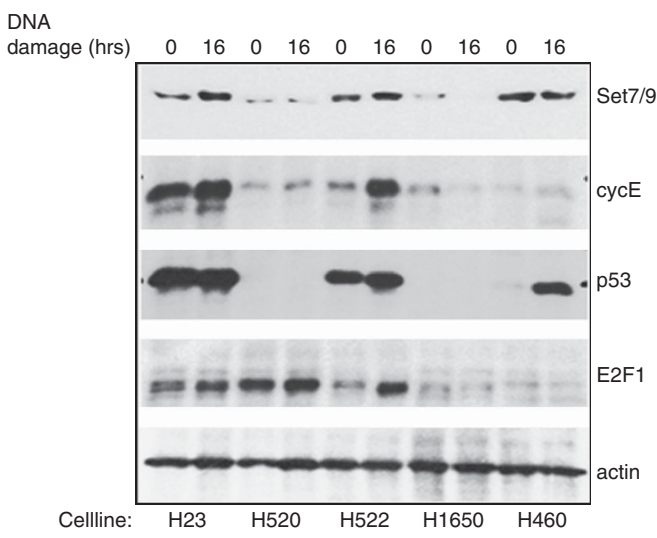

d

DNA

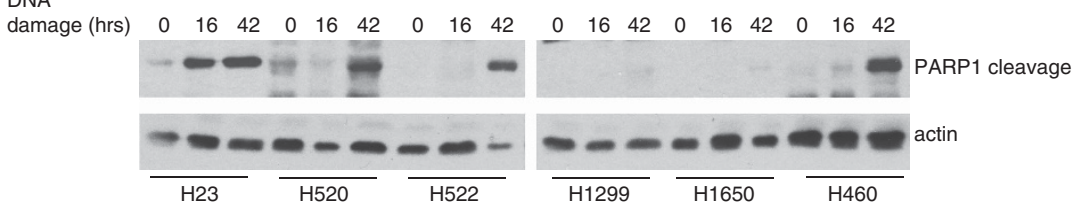

b

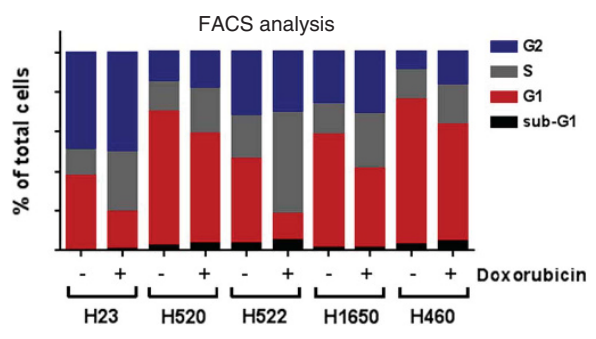

C $\mathrm{H} 522$ cells

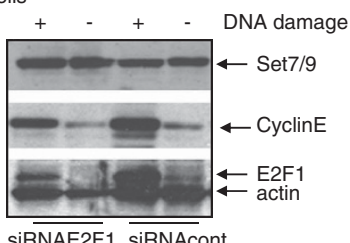

Figure 6 Analysis of different lung tumour cell lines reveals variable expression of Set7/9, E2F1, and cyclin E. (a) The panel of indicated lung tumour cell lines were treated with doxorubicin for the indicated periods of time and analysed for Set7/9, cyclin E, p53, and E2F1 levels. Actin was used as a loading control. (b) The same cell lines treated similarly as in (a) were also analysed by FACS for cell-cycle distribution. (c) H522 cells were treated with E2F1-specific or scramble siRNA followed by doxorubicin treatment to induce DNA damage. Treated cells were assayed for the levels of Set7/9, cyclin E, and E2F1 protein expression. Actin signal was used for normalisation. (d) The cell lines used in A were treated for various times with doxorubicin and analysed by western for the presence of the PARP cleavage product (marker of apoptosis)

but not on the presence of Set7/9 (Figure 6d, compare H23, $\mathrm{H} 520$, H522, and H460), reiterating our results on Set7/9mediated repression of TP73 expression (Figure $3 \mathrm{~g}$ ). Thus, our results strongly argue that the Set7/9-E2F1 axis, by driving the expression of cyclin $\mathrm{E}$, has an important role in cellcycle regulation of lung cancer cells upon DNA damage.

\section{Discussion}

Lysine methylation of histones has an important role in cellcycle progression and DDR. ${ }^{1,56}$ However, recently published reports suggest that methylation of non-histone targets is also instrumental in these processes. Several KMTases, besides Set7/9, were found to methylate important cell-cycle regulators $\left(\mathrm{Rb}^{57} \mathrm{p} 53,^{58,59}\right.$ heat shock protein $\left.90(\mathrm{HSP} 90)^{60,61}\right)$. In this study, we show that Set7/9 has a critical role in regulation of cell cycle by promoting E2F1-dependent transcription of the CCNE1 gene upon DNA damage. Previously, we have reported that Set7/9 affected cell cycle in a p53-dependent manner. ${ }^{6}$ Thus, we hypothesised that the loss of Set7/9 would result in G2/M arrest. However, despite the lower level of p21 expression in Set7/9KD cells versus control cells (data not shown and Ivanov et al. ${ }^{6}$ ), we observed a profound arrest of Set7/9- cells in G1/S. This effect was due to attenuation of cyclin E expression. Importantly, we found that this phenomenon was p53 independent, but E2F1 dependent, and was reproducible upon treatment with different forms of DNA damage, including doxorubicin, gamma- and UV-irradiation.
How is E2F1 activity regulated by Set7/9? Previously, methylation of E2F1 by Set7/9 was reported to attenuate its protein stability via increased poly-ubiquitylation and subsequent degradation by $26 \mathrm{~S}$ proteasome. ${ }^{17} \mathrm{An}$ apparently contradictory report from Xie et al. ${ }^{62}$ suggests that Set7/9 stabilises and activates the E2F1 transcription factor in response to DNA damage. Our data show that, in agreement with previously reported data, ${ }^{17}$ Set7/9 indeed attenuates the level of E2F1 expression. However, Set7/9 is required for the transcriptional activity of E2F1, thus forming a regulatory loop (Figure 7). This type of negative feedback regulation is widespread in nature. For example, yeast activator Gal4 needs to by ubiquitinylated for its full transcriptional activity, which subsequently causes its degradation. ${ }^{63}$

Interestingly, we found that Set7/9 inversely regulates the E2F1 target genes, CCNE1 and TP73 (Figures 3 and 4). These results indicate that Set7/9 is likely situated upstream of E2F1 and coordinates the final transcriptional outcome. Future studies should shed light on the molecular mechanisms of this regulation.

Our findings on the Set7/9-E2F1-cyclin E axis have important ramifications for general understanding of the molecular mechanisms of tumourigenesis, bearing in mind that E2F1-dependent overexpression of cyclin E is considered to be a 'classical' oncogenic insult causing DDR as an anti-oncogenic barrier. ${ }^{64}$ The fact that the genetic abrogation of Set7/9 in non-transformed cells ${ }^{7,8}$ does not affect their cell cycle or survival, makes Set7/9 a very attractive 


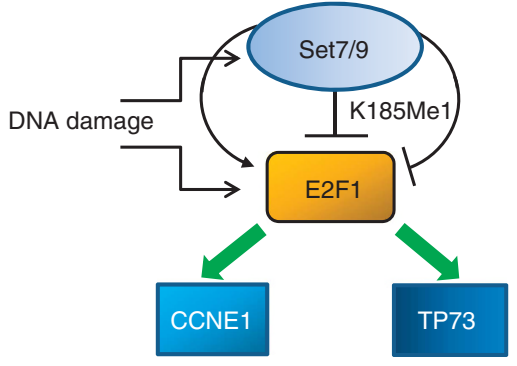

Figure 7 Set7/9 differentially regulates E2F1-dependent genes in response to DNA damage. A model depicts the effect of Set7/9 on E2F1 activity. On the one hand, Set7/9 co-activates E2F1-dependent transcription of CCNE1 gene (left). On the other hand, Set7/9 represses E2F1-dependent transcription of Tp73 (right). In addition, Set7/9-mediated methylation of E2F1 on k185 results in de-stabilisation of the latter

pharmacological target in tumours that are critically dependent on cyclin E levels. ${ }^{65}$

\section{Materials and Methods}

Cell line manipulations. All cells used in this study were purchased from ATCC (Manassas, VA, USA), if not stated otherwise. Human lung adenocarcinoma cell lines H1299, H23, H520, H522, H1650, and H460 were propagated in Roswell Park Memorial Institute (RPMI) medium (Gibco, Carlsbad, CA, USA) supplemented with $10 \%$ foetal bovine serum (FBS) (Gibco). Human osteosarcoma cell line U2-OS and its derivatives as well as human embryonic kidney cell line HEK-293 were maintained in Dulbecco's modified Eagle's medium (DMEM) (Gibco) supplemented with 10\% FBS (Gibco). Cells were grown at $37^{\circ} \mathrm{C}$ in a humidified atmosphere with $5 \% \mathrm{CO}_{2}$. U2-OS cells with stable expression of shRNA against Set7/9 and p53 were obtained by lentiviral infection as described previously ${ }^{16}$ (Lezina CDDs, 2013). U2-OS cells with inducible expression of shRNA against Set7/9 and the reference cell line were generated from the commercially available U2-OS Tet-On cells (Clontech/Takara Bio Company, Mountain View, CA, USA) stably transfected with $p S$ uperior or pSuperior-shRNA-Set7/9, respectively. Details of the cloning are available upon request.

E2F1 knockdown by specific siRNA. Downregulation of E2F1 expression was achieved by transfecting cells with specific siRNA against E2F1 as previously described. ${ }^{17,66}$ Scrambled siRNA against luciferase served as a negative control. Cells were seeded on $60 \mathrm{~mm}$ dishes and were transfected the following day with $100 \mathrm{nM}$ of the corresponding si-RNA using Lipofectamine 2000 (Invitrogen, Carlsbad, CA, USA) according to the manufacturer's instructions. Cells were harvested $24 \mathrm{~h}$ after transfection.

Cdk2 and Cdk4 kinase activity. $5 \times 10 \mathrm{E} 6$ of U2-OS parental control cells and cells with knockdown expression of Set7/9 and p53 were treated with doxorubicin for the indicated times and subject to lysis in radioimmunoprecipitation assay (RIPA) buffer. The resulting extracts were incubated overnight at $+4^{\circ} \mathrm{C}$ with $1 \mu \mathrm{g}$ of anti-cdk2 or anti-cdk4 antibodies (Santa Cruz Biotechnology, Santa Cruz, CA, USA) in the presence of phosphatase inhibitors (Roche, Basel, Switzerland). Following morning the immunoprecipitated complexes were recovered by adding $20 \mu \mathrm{l}$ of protein A beads (Repligen, Waltham, MA, USA) Following washes with RIPA buffer, the cdk2/cyclin E and cdk4/cyclin D complexes were incubated in the presence of $\gamma$-[P $\left.\mathrm{P}^{32}\right]$-ATP and the recombinant histone $\mathrm{H} 1$ protein for $30 \mathrm{~min}$ at room temperature. The radioactively labelled phosphorylated $\mathrm{H} 1$ proteins were separated by SDS-polyacrylamide gel electrophoresis (SDSPAGE), dried, and exposed with film.

RNA isolation and relative quantification RT-PCR. Total RNA was extracted from the cultured cells using the TRIzol Reagent (Invitrogen) according to the manufacturer's instructions. For relative quantification RT-PCR analysis of p21, CCNE1, TP73, and $\beta$-actin mRNA, $1 \mu \mathrm{g}$ of total RNA was reverse transcribed to cDNA with oligod(T) using Ready-to-Go kit (GE Healthcare, Amersham, UK). Then real-time PCR was performed on an RotorGene 6000 PCR machine
(Qiagene, Hilden, Germany) using SYBR green dye (Invitrogen). The 20- $\mu$ PCR reaction included $1 \mu \mathrm{l}$ RT product, $1 \times$ QuantiTect SYBR green PCR Master Mix, and $0.5 \mu \mathrm{M}$ each sense and antisense primers. The reactions were incubated in a 96-well plate at $95^{\circ} \mathrm{C}$ for $5 \mathrm{~min}$, followed by 40 cycles of $95^{\circ} \mathrm{C}$ for $30 \mathrm{~s}, 60^{\circ} \mathrm{C}$ for $30 \mathrm{~s}$, and $72^{\circ} \mathrm{C}$ for $30 \mathrm{~s}$. All reactions were run in triplicate. After the reactions, the $C_{T}$ values were determined using fixed threshold settings. Relative amounts of p21, CCNE1, and TP73 mRNAs were normalised to $\beta$-actin mRNA. Expression of these genes was analysed by RT-PCR using the following primers: (p21) 5-gacaccactggagggtgact, 3-ctcttggagaagatcagccg; (CCNE1) 5-caaactcaacgtg caagcctc, 3-gcccagctcagtacaggcag; (TP73) 5-cacgtttgagcacctctgga, and 3-gaactg ggccatgacagatg. Primers to $\beta$-actin were purchased from PrimerDesign, (Southampton, UK).

ChIP assay. ChIP assays were performed as described previously ${ }^{46}$ Briefly, $3 \times 10^{6}$ cells per sample were crosslinked with $1 \%$ formaldehyde for $15 \mathrm{~min}$. Crosslinking was neutralised with $0.125 \mathrm{M}$ glycine, and cells were scraped in phosphate buffer saline (PBS). Chromatin was sonicated using the Diagenode (Liège, Belgium) Bioruptor for $15 \mathrm{~min}$ with 30 -s pulse/pause cycles in polycarbonate tubes on ice to shear chromatin to 300 - to 600 -bp fragments. Unsheared debris was spun down, and then the chromatin was incubated overnight with the appropriate antisera, concurrent with the blocking of protein G-Sepharose beads using $2.5 \%$ bovine serum albumin (BSA). Immune complexes were then precipitated using 'blocked' protein $\mathrm{G}$ beads for $4 \mathrm{~h}$ at $4^{\circ} \mathrm{C}$, washed three times, and then eluted. Immunoprecipitated DNA was purified and quantitative PCR was performed with $1 \mu$ of DNA to assess E2F1 binding and modified histone levels. The following antibodies were used: antibodies for CHIP: HDAC2 (Millipore 05-814, Billerica, MA, USA), anti-E2F-1 (clones KH2O and KH95, Millipore 05-379), anti-Histone H3-K4me1 (Abcam ab8895, Cambridge, UK), anti-acetyl-Histone H3 (Millipore 06-599), anti-acetyl-Histone H4 (Millipore 06866), and anti-H3K9me3 (Diagenode C15410056). To examine the binding of E2F1 and histone modifications of CCNE1 and TP73 the following primers were used: $\mathrm{cycE}-0.4 \mathrm{~Kb}$ up start site (in close proximity of E2F1 biding site): F-ACACATCCCCTTGGCTCA; R-CGGGTGGAATGTAAACACG; TP73 - $1 \mathrm{~Kb}$ upstream of the start site: F-TGAGCCATGAAGATGTGCGAG; R-GCTGCTTATGG TCTGATGCTTATG.

Western blotting. p53, E2F1, Cdk2, Cyclin E, Cdk4, cyclin D and Wee1 protein levels were quantified by western blot analysis of whole-cell extracts using antibodies against the corresponding proteins. These samples were normalised by blotting with an antibody against $\alpha$-tubulin. The following antibodies were used: Anti-p53 (Ab-6, Oncogene, San Diego, CA, USA), anti-Cyclin E (sc-15254, Santa Cruz Biotechnology), anti-E2F1 (Millipore), Cdk2, cyclin D, Cdk4 (Santa Cruz Biotechnology), and anti- $\alpha$-actin (B-7, Santa Cruz Biotechnology).

Luciferase assay of 3-UTR constructs. The luciferase reporter plasmids with wild-type CCNE1 promoter and its E2F1 binding-deficient variants were kindly provided by JR Nevins laboratory. For luciferase reporter assays, cells were cultured in 6-well plates, and each well was transfected with $0.5 \mu \mathrm{g}$ of luciferase reporter plasmid, $0.5 \mu \mathrm{g}$ of $\beta$-galactosidase expression plasmid (Ambion, Life Technologies, Carlsbad, CA, USA), and equal amounts of scrambled negative control RNA, pre-miR-26a, pre-miR-16, or anti-miR-16 using Lipofectamine 2000 (Invitrogen). The $\beta$-galactosidase plasmid was used as a transfection control. At $24 \mathrm{~h}$ post transfection, cells were assayed using luciferase assay kits (Promega, Madison, WI, USA). The data depicted are representative of three independent experiments performed on different days.

Cell-cycle analysis and BrdU staining. Cells were harvested, washed once with PBS, and fixed in $70 \%$ ethanol overnight. Staining for DNA content was performed with $50 \mu \mathrm{g} / \mathrm{ml}$ propidium iodide and $1 \mu \mathrm{g} / \mathrm{ml}$ RNase A for $30 \mathrm{~min}$. Analysis was performed on a FACS Canto II flow cytometer (BD Biosciences, Franklin Lakes, NJ, USA) with the Cell Quest Pro software. Cell-cycle modelling was performed with the Modfit 3.0 software (Verity Software House, Topsham, ME, USA).

Staining of the cells with BrdU was carried out with the FITS BrdU Flow kit according to the manufacturer's instructions (BD Pharmingen, Franklin Lakes, NJ, USA). Briefly, $5 \times 10$ E5 U2-OS and U2-OS Set7/9KD cells were non-treated or pulse-treated with $0.1 \mu \mathrm{M}$ of doxorubicin at the indicated time points, washed with PBS with subsequent labelling with $10 \mu \mathrm{M}$ BrdU. Following the incubation, cells were fixed with $0.5 \%$ paraformaldehyde, permeabilised, treated with DNAse I, 
incubated with anti-BrdU-FITS conjugated antibody and stained with 7-AAD to visualise DNA. The resulting samples were analysed by fluorescence-activated cell sorting (FACS).

Statistical analysis. All presented images of western blotting and cell-cycle assay are representative of at least three independent experiments. Relative quantification RT-PCR, luciferase reporter, and cell viability assays were performed in triplicate, and each experiment was repeated three to five times. The data shown are the mean \pm S.D. of at least three independent experiments. Statistical significance was considered at $P<0.05$ using the Student's t-test.

Immunofluorescence microscopy. Mitotic U2-OS or U2-OS Set7/9KD cells were detected by staining with anti-phospho-Histone H3 (Ser10) antibodies conjugated with Alexa 647 (Cell Signaling, Danvers, MA, USA; \#9716). The nuclei were visualised with Hoechst 33342 dye (Sigma, St. Louis, MO, USA; 14533). Cell plates were analysed using an automated Operetta Imaging System (PerkinElmer, Waltham, MA, USA) at $\times 20$ magnification with the Harmony 3.1 software (Perkin-Elmer). To calculate main readout values (number of cells, fraction of cells in M-phase) RMS Cell Cycle Classification application (Perkin-Elmer) was used. The 23 independent fields were analysed in all wells of four independent replicates. The percentage of mitotic cells was calculated as a ratio of all M-phase positive cells to all cells in the well.

\section{Conflict of Interest}

The authors declare no conflict of interest.

Acknowledgements. This work was supported by MRC and by the Russian Ministry of Education (11.G34.31.0069) to GM and the Russian Foundation for Basic Research (A_2013 13-04-01024) and the Programme in Molecular and Cellular Biology from the Russian Academy of Sciences to NB.

1. Morgunkova A, Barlev NA. Lysine methylation goes global. Cell Cycle 2006; 5: 1308-1312.

2. Su IH, Tarakhovsky A. Lysine methylation and 'signaling memory'. Curr Opin Immunol 2006; 18: 152-157.

3. Pradhan S, Chin HG, Esteve PO, Jacobsen SE. SET7/9 mediated methylation of non-histone proteins in mammalian cells. Epigenetics 2009; 4: 383-387.

4. Nishioka K, Rice JC, Sarma K, Erdjument-Bromage H, Werner J, Wang Y et al. PR-Set7 is a nucleosome-specific methyltransferase that modifies lysine 20 of histone $\mathrm{H} 4$ and is associated with silent chromatin. Mol Cell 2002; 9: 1201-1213.

5. Wang H, Cao R, Xia L, Erdjument-Bromage H, Borchers C, Tempst $P$ et al. Purification and functional characterization of a histone $\mathrm{H} 3$-lysine 4-specific methyltransferase. Mol Cell 2001; 8: 1207-1217

6. Ivanov GS, Ivanova T, Kurash J, Ivanov A, Chuikov S, Gizatullin F et al. Methylationacetylation interplay activates p53 in response to DNA damage. Mol Cell Biol 2007; 27 $6756-6769$

7. Lehnertz B, Rogalski JC, Schulze FM, Yi L, Lin S, Kast J et al. p53-dependent transcription and tumor suppression are not affected in Set7/9-deficient mice. Mol Cell 2011; 43 673-680.

8. Campaner S, Spreafico F, Burgold T, Doni M, Rosato U, Amati B et al. The methyltransferase Set7/9 (Setd7) is dispensable for the p53-mediated DNA damage response in vivo. Mol Cell 2011; 43: 681-688.

9. Kouskouti A, Scheer E, Staub A, Tora L, Talianidis I. Gene-specific modulation of TAF10 function by SET9-mediated methylation. Mol Cell 2004; 14: 175-182.

10. Subramanian K, Jia D, Kapoor-Vazirani P, Powell DR, Collins RE, Sharma D et al. Regulation of estrogen receptor alpha by the SET7 lysine methyltransferase. Mol Cell 2008; 30: 336-347.

11. Ea CK, Baltimore D. Regulation of NF-kappaB activity through lysine monomethylation of p65. Proc Natl Acad Sci USA 2009; 106: 18972-18977.

12. Masatsugu T, Yamamoto K. Multiple lysine methylation of PCAF by Set9 methyltransferase. Biochem Biophys Res Commun 2009; 381: 22-26.

13. Yang J, Huang J, Dasgupta M, Sears N, Miyagi M, Wang B et al. Reversible methylation of promoter-bound STAT3 by histone-modifying enzymes. Proc Natl Acad Sci USA 2010; 107: 21499-21504

14. Oudhoff MJ, Freeman SA, Couzens AL, Antignano F, Kuznetsova E, Min PH et al. Control of the hippo pathway by Set7-dependent methylation of Yap. Dev Cell 2013; 26: 188-194.

15. Wang D, Zhou J, Liu X, Lu D, Shen C, Du Y et al. Methylation of SUV39H1 by SET7/9 results in heterochromatin relaxation and genome instability. Proc Natl Acad Sci USA 2013; 110: $5516-5521$

16. Chuikov S, Kurash Y, Wilson JR, Xiao B, Justin N, Ivanov G et al. Regulation of p53 activity through lysine methylation. Nature 2004; 432: 353-360.
17. Kontaki $\mathrm{H}$, Talianidis I. Lysine methylation regulates E2F1-induced cell death. Mol Cell 2010; 39: 152-160.

18. Agarwal ML, Agarwal A, Taylor WR, Stark GR. p53 controls both the G2/M and the G1 cell cycle checkpoints and mediates reversible growth arrest in human fibroblasts. Proc Natl Acad Sci USA 1995; 92: 8493-8497.

19. Linke SP, Clarkin KC, Di Leonardo A, Tsou A, Wahl GM. A reversible, p53-dependent GO G1 cell cycle arrest induced by ribonucleotide depletion in the absence of detectable DNA damage. Genes Dev 1996; 10: 934-947.

20. Di Leonardo A, Linke SP, Clarkin K, Wahl GM. DNA damage triggers a prolonged p53-dependent $\mathrm{G} 1$ arrest and long-term induction of Cip1 in normal human fibroblasts. Genes Dev 1994; 8: 2540-2551.

21. Geske FJ, Nelson AC, Lieberman R, Strange R, Sun T, Gerschenson LE. DNA repair is activated in early stages of p53-induced apoptosis. Cell Death Differ 2000; 7: 393-401.

22. Johnson DG, Schwarz JK, Cress WD, Nevins JR. Expression of transcription factor E2F1 induces quiescent cells to enter S phase. Nature 1993; 365: 349-352.

23. Polager S, Ginsberg D. p53 and E2f: partners in life and death. Nat Rev Cancer 2009; 9: 738-748.

24. Chellappan SP, Hiebert S, Mudryj M, Horowitz JM, Nevins JR. The E2F transcription factor is a cellular target for the RB protein. Cell 1991; 65: 1053-1061.

25. Nevins JR, Chellappan SP, Mudryj M, Hiebert S, Devoto S, Horowitz J et al. E2F transcription factor is a target for the RB protein and the cyclin A protein. Cold Spring Harb Symp Quant Biol 1991; 56: 157-162.

26. Helin K, Harlow E, Fattaey A. Inhibition of E2F-1 transactivation by direct binding of the retinoblastoma protein. Mol Cell Biol 1993; 13: 6501-6508.

27. Helin $\mathrm{K}, \mathrm{Ed} \mathrm{H}$. The retinoblastoma protein as a transcriptional repressor. Trends Cell Biol, 1993; 3(2): 43-46.

28. Berthet C, Klarmann KD, Hilton MB, Suh HC, Keller JR, Kiyokawa H et al. Combined loss of Cdk2 and Cdk4 results in embryonic lethality and Rb hypophosphorylation. Dev Cell 2006; 10: $563-573$.

29. Braden WA, Lenihan JM, Lan Z, Luce KS, Zagorski W, Bosco E et al. Distinct action of the retinoblastoma pathway on the DNA replication machinery defines specific roles for cyclindependent kinase complexes in prereplication complex assembly and S-phase progression. Mol Cell Biol 2006; 26: 7667-7681.

30. Koff A, Giordano A, Desai D, Yamashita K, Harper JW, Elledge S et al. Formation and activation of a cyclin E-cdk2 complex during the $\mathrm{G} 1$ phase of the human cell cycle. Science 1992; 257: 1689-1694.

31. Braden WA, McClendon AK, Knudsen ES. Cyclin-dependent kinase $4 / 6$ activity is a critical determinant of pre-replication complex assembly. Oncogene 2008; 27: 7083-7093.

32. Dyson N. The regulation of E2F by pRB-family proteins. Genes Dev 1998; 12: 2245-2262.

33. Ren B, Cam H, Takahashi Y, Volkert T, Terragni J, Young RA et al. E2F integrates cell cycle progression with DNA repair, replication, and G(2)/M checkpoints. Genes Dev 2002; 16: $245-256$.

34. DeGregori J, Kowalik T, Nevins JR. Cellular targets for activation by the E2F1 transcription factor include DNA synthesis- and G1/S-regulatory genes. Mol Cell Biol 1995; 15: 4215-4224.

35. Pan H, Yin C, Dyson NJ, Harlow E, Yamasaki L, Van Dyke T. Key roles for E2F1 in signaling p53-dependent apoptosis and in cell division within developing tumors. Mol Cell 1998; 2: 283-292

36. Taura M, Suico MA, Fukuda R, Koga T, Shuto T, Sato T et al. MEF/ELF4 transactivation by E2F1 is inhibited by p53. Nucleic Acids Res 2011; 39: 76-88.

37. Marouco D, Garabadgiu AV, Melino G, Barlev NA. Lysine-specific modifications of p53: a matter of life and death? Oncotarget 2013; Vol 4: 1556-1571.

38. Mittenberg AG, Moiseeva TN, Barlev NA. Role of proteasomes in transcription and their regulation by covalent modifications. Front Biosci 2008; 13: 7184-7192.

39. Moiseeva TN, Bottrill A, Melino G, Barlev NA. DNA damage-induced ubiquitylation of proteasome controls its proteolytic activity. Oncotarget 2013; 4: 1338-1348.

40. Esteve PO, Chin HG, Benner J, Feehery GR, Samaranayake M, Horwitz GA et al Regulation of DNMT1 stability through SET7-mediated lysine methylation in mammalian cells. Proc Natl Acad Sci USA 2009; 106: 5076-5081.

41. Yang XD, Huang B, Li M, Lamb A, Kelleher NL, Chen LF. Negative regulation of NFkappaB action by Set9-mediated lysine methylation of the RelA subunit. EMBO J 2009; 28: $1055-1066$.

42. Kleiblova P, Shaltiel IA, Benada J, Sevcik J, Pechackova S, Pohlreich $P$ et al. Gain-of-function mutations of PPM1D/Wip1 impair the p53-dependent G1 checkpoint J Cell Biol 2013; 201: 511-521.

43. Errico A, Deshmukh K, Tanaka Y, Pozniakovsky A, Hunt T. Identification of substrates for cyclin dependent kinases. Adv Enzyme Regul 2010; 50: 375-399.

44. Dulic V, Kaufmann WK, Wilson SJ, Tlsty TD, Lees E, Harper JW et al. p53-dependent inhibition of cyclin-dependent kinase activities in human fibroblasts during radiationinduced G1 arrest. Cell 1994; 76: 1013-1023.

45. Evans T, Rosenthal ET, Youngblom J, Distel D, Hunt T. Cyclin: a protein specified by maternal mRNA in sea urchin eggs that is destroyed at each cleavage division. Cell 1983; 33: 389-396.

46. Lezina L, Purmessur N, Antonov AV, Ivanova T, Karpova E, Krishan K et al. miR-16 and miR-26a target checkpoint kinases Wee1 and Chk1 in response to p53 activation by genotoxic stress. Cell Death Dis 2013; 4: e953. 
47. Wunderlich M, Berberich SJ. Mdm2 inhibition of p53 induces E2F1 transactivation via p21. Oncogene 2002; 21: 4414-4421.

48. Kelly RD, Cowley SM. The physiological roles of histone deacetylase (HDAC) 1 and 2 : complex co-stars with multiple leading parts. Biochem Soc Trans 2013; 41: 741-749.

49. Hallstrom TC, Mori S, Nevins JR. An E2F1-dependent gene expression program that determines the balance between proliferation and cell death. Cancer Cell 2008; 13: $11-22$.

50. Johnson DG, Degregori J. Putting the oncogenic and tumor suppressive activities of E2F into context. Curr Mol Med 2006; 6: 731-738.

51. Antonov AV. BioProfiling.de: analytical web portal for high-throughput cell biology. Nucleic Acids Res 2011; 39: W323-W327.

52. Antonov AV, Knight RA, Melino G, Barlev NA, Tsvetkov PO. MIRUMIR: an online tool to test microRNAs as biomarkers to predict survival in cancer using multiple clinical data sets. Cell Death Differ 2013; 20: 367-367.

53. Eymin B, Gazzeri S, Brambilla C, Brambilla E. Distinct pattern of E2F1 expression in human lung tumours: E2F1 is upregulated in small cell lung carcinoma. Oncogene 2001; 20: $1678-1687$.

54. Huang CL, Liu D, Nakano J, Yokomise H, Ueno M, Kadota K et al. E2F1 overexpression correlates with thymidylate synthase and survivin gene expressions and tumor proliferation in non small-cell lung cancer. Clin Cancer Res 2007; 13: 6938-6946.

55. Celardo I, Grespi F, Antonov A, Bernassola F, Garabadgiu AV, Melino G et al. Caspase- 1 is a novel target of p63 in tumor suppression. Cell Death Dis 2013; 4: e645.

56. Black JC, Van Rechem C, Whetstine JR. Histone lysine methylation dynamics: establishment, regulation, and biological impact. Mol Cell 2012; 48: 491-507.
57. Saddic LA, West LE, Aslanian A, Yates JR 3rd, Rubin SM, Gozani 0 et al. Methylation of the retinoblastoma tumor suppressor by SMYD2. J Biol Chem 2010; 285: 37733-37740.

58. Huang J, Perez-Burgos L, Placek BJ, Sengupta R, Richter M, Dorsey JA et al. Repression of p53 activity by Smyd2-mediated methylation. Nature 2006; 444: 629-632.

59. Shi X, Kachirskaia I, Yamaguchi H, West LE, Wen H, Wang EW et al. Modulation of p53 function by SET8-mediated methylation at lysine 382. Mol Cell 2007; 27: 636-646.

60. Abu-Farha M, Lanouette S, Elisma F, Tremblay V, Butson J, Figeys D et al. Proteomic analyses of the SMYD family interactomes identify HSP90 as a novel target for SMYD2. $\mathrm{J}$ Mol Cell Biol 2011; 3: 301-308.

61. Burrows F, Zhang H, Kamal A. Hsp90 activation and cell cycle regulation. Cell Cycle 2004; 3: $1530-1536$.

62. Xie Q, Bai Y, Wu J, Sun Y, Wang Y, Zhang $Y$ et al. Methylation-mediated regulation of E2F1 in DNA damage-induced cell death. $J$ Recept Signal Transduct Res 2011; 31: 139-146.

63. Muratani M, Kung C, Shokat KM, Tansey WP. The F box protein Dsg1/Mdm30 is a transcriptional coactivator that stimulates Gal4 turnover and cotranscriptional mRNA processing. Cell 2005; 120: 887-899.

64. Bartkova J, Horejsi Z, Koed K, Kramer A, Tort F, Zieger K et al. DNA damage response as a candidate anti-cancer barrier in early human tumorigenesis. Nature 2005; 434: 864-870.

65. Keyomarsi K, Tucker SL, Buchholz TA, Callister M, Ding Y, Hortobagyi GN et al. Cyclin E and survival in patients with breast cancer. N Engl J Med 2002; 347: 1566-1575.

66. Dapas B, Farra R, Grassi M, Giansante C, Fiotti N, Uxa L et al. Role of E2F1-cyclin E1-cyclin E2 circuit in human coronary smooth muscle cell proliferation and therapeutic potential of its downregulation by siRNAs. Mol Med 2009; 15: 297-306.

\section{Supplementary Information accompanies this paper on Cell Death and Differentiation website (http://www.nature.com/cdd)}

